BMJ Open

Diabetes

Research

\& Care

\title{
Risk factors for 30-day readmission following hypoglycemia-related emergency room and inpatient admissions
}

\author{
M F Emons, ${ }^{1} \mathrm{~J}$ P Bae, ${ }^{2}$ B J Hoogwerf, ${ }^{2}$ S L Kindermann, ${ }^{1}$ R J Taylor, ${ }^{1}$ \\ $\mathrm{B} \mathrm{H}$ Nathanson ${ }^{3}$
}

To cite: Emons MF, Bae JP, Hoogwerf BJ, et al. Risk factors for 30-day readmission following hypoglycemia-related emergency room and inpatient admissions. BMJ Open Diabetes Research and Care 2016;4:e000160. doi:10.1136/bmjdrc-2015000160

- Additional material is available. To view please visit the journal (http://dx.doi.org/ 10.1136/bmjdrc-2015000160).

Received 6 October 2015 Revised 29 January 2016 Accepted 4 March 2016

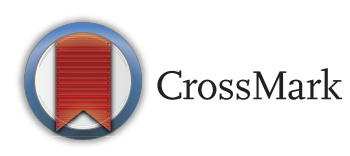

${ }^{1}$ Cerner Corporation Eli Lilly and Company ${ }^{3}$ OptiStatim, LLC

Correspondence to Dr SL Kindermann; sylvia.kindermann@cerner. com

\section{ABSTRACT}

Objective: Hypoglycemia is a serious complication of diabetes treatment. This retrospective observational study characterized hypoglycemia-related hospital emergency room (ER) and inpatient (in-pt) admissions and identified risk factors for 30-day all-cause and hypoglycemia-related readmission.

Research design and methods: 4476

hypoglycemia-related ER and in-pt encounters with discharge dates from 1/1/2009 to 3/31/2014 were identified in a large, multicenter electronic health record database. Outcomes were 30-day all-cause ER/ hospital readmission and hypoglycemia-related readmission. Multivariable logistic regression methods identified risk factors for both outcomes.

Results: 1095 (24.5\%) encounters had ER/hospital all-cause readmission within 30 days and 158 (14.4\%) of these were hypoglycemia-related. Predictors of allcause 30-day readmission included recent exposure to a hospital/nursing home (NH)/skilled nursing facility (SNF; OR 1.985, $p<0.001$ ); age 25-34 and 35-44 (OR 2.334 and 1.996 , respectively, compared with age $65-$ 74 , both $p<0.001$ ); and African-American $(A A)$ race versus all other race categories ( $O R$ 1.427, $p=0.011)$. Other factors positively associated with readmission include chronic obstructive pulmonary disease, cerebrovascular disease, cardiac dysrhythmias, congestive heart disease, hypertension, and mood disorders. Predictors of readmissions attributable to hypoglycemia included recent exposure to a hospital/ NH/SNF (OR 2.299, $p<0.001$ ), AA race (OR 1.722 , $\mathrm{p}=0.002$ ), age 35-44 (OR 3.484, compared with age 65-74, $p<0.001$ ), hypertension (OR 1.891, $p=0.019$ ), and delirium/dementia and other cognitive disorders (OR 1.794, $\mathrm{p}=0.038$ ). Obesity was protective against 30-day hypoglycemia-related readmission (OR 0.505 , $\mathrm{p}=0.017$ ).

Conclusions: Factors associated with 30-day all-cause and hypoglycemia-related readmission among patients with diabetic hypoglycemia include recent exposure to hospital/SNF/NH, adults $<45$ years, AAs, and several cardiovascular and respiratory-related comorbid conditions.

Hypoglycemia is a common, serious complication of diabetes treatment. Typical causes of hypoglycemia in patients with diabetes include use of insulin or diabetes medications, missed meals or inadequate caloric intake, and alcohol consumption. Hypoglycemia may contribute to the risk of cardiovascular events ${ }^{1-3}$ and is associated with increased morbidity and mortality. ${ }^{4-9}$

Severe hypoglycemia in diabetes is defined as an event requiring the assistance of others. ${ }^{10}$ Although only a portion of severe hypoglycemic episodes present to the emergency room (ER) or hospital, ${ }^{11}$ resource utilization related to these events reflect the significant burden on the healthcare system. $^{12}{ }^{13}$ Further, research indicates that fear of hypoglycemic events reduces adherence to prescribed antidiabetic regimens. ${ }^{14}$

Prior studies on hospital-based ER and inpatient (in-pt) admissions for hypoglycemia have largely focused on a specific treatment setting, diabetes type, age group, or geographic region. ${ }^{15}{ }^{16}$ However, the risk factors associated with 30-day readmission to the ER or hospital (ER/hospital) after a hypoglycemia-related ER or hospital admission have not been well established. Thirty-day readmission has become an important hospital performance measure used by the Centers for Medicare \& Medicaid Services. ${ }^{17}$ In this study, we characterize hospital ER/hospital admissions related to hypoglycemia and identify risk factors for 30-day ER/hospital readmission using a large, contemporary multicenter database.

\section{RESEARCH DESIGN AND METHODS}

This retrospective observational study used data collected from US-based hospitals in Cerner Health Facts, an electronic health record database which contains a comprehensive clinical record for each encounter that includes time-stamped medication 
orders and laboratory, admission, and billing information from affiliated patient care settings. Cerner Corporation has established Health Insurance Portability and Accountability Act-compliant operating policies to ensure de-identification of the Health Facts database.

Qualifying hypoglycemia-related ER/hospital encounters with discharge dates from $1 / 1 / 2009$ through $3 / 31 /$ 2014 from facilities providing $24 \mathrm{~h}$ ER services were selected. Patients were $\geq 6$ years of age and had documented diabetes in the study encounter or within the preceding 12 months. Hypoglycemia-related ER/hospital encounters were defined by International Classification of Diseases, Ninth Revision, Clinical Modification (ICD-9-CM) codes as follows:

- A primary diagnosis of hypoglycemic coma (251.0), other unspecified hypoglycemia (251.1), OR

- A primary diagnosis of diabetes with other coma (250.3) $A N D$ a secondary diagnosis of hypoglycemic coma (251.0), other unspecified hypoglycemia (251.1), or hypoglycemia unspecified (251.2) WITHOUT a secondary diagnosis of secondary diabetes mellitus with ketoacidosis $(249.1 \mathrm{x})$ or diabetes with ketoacidosis (250.1x).

Exclusion criteria were pregnancy, lack of at least one blood glucose laboratory value during the study encounter or transfer from an acute care facility. Patients with an ER visit immediately preceding the in-pt encounter were counted as in-pts, and their ER data were merged to create one hospital encounter. Comorbid conditions were defined by 2014 Healthcare Cost and Utilization Project Clinical Classifications Software (HCUP CCS). ${ }^{18}$ Patients could have more than one study encounter, but encounters with a discharge disposition of expired or unknown at the time of the first encounter were excluded, such that only surviving patients were included in the study for follow-up.

The primary end point was all-cause readmission to the ER/hospital within 30 days, and the secondary end point was hypoglycemia-related readmission within 30 days with hypoglycemia defined as above (ie, a primary diagnosis of 251.0 or 251.1; or a primary diagnosis of 250.3 and a secondary diagnosis of 251.0, 251.1, or 251.2 without a secondary diagnosis of $249.1 \mathrm{x}$ or $250.1 \mathrm{x})$. Findings were stratified by readmission type and were reported as either proportions for binary variables, or means and SDs or medians and IQRs for continuous variables. The $t$ test for means or the $z$-test for proportions were used to derive $p$ values, after adjusting for the within-participant correlation for patients with multiple encounters. ${ }^{19}{ }^{20} \mathrm{p}$ Values $<0.05$ were defined to be statistically significant.

In the multivariable analyses used to identify factors predictive of all-cause readmission and of hypoglycemiarelated readmission, multiple iterations of a stepwise bootstrapping procedure ranked variables based on the number of times they entered bootstrapped samples of the data set. ${ }^{21}$ To strike a balance between model performance and parsimony, potential nested models were compared with Bayesian Information Criterion statistics. ${ }^{22}$ For continuous variables (eg, age) the predictor was modeled both as a continuous linear variable and as a categorical variable when the relationship between the predictor and outcome appeared to be non-linear. A multilevel hierarchical multivariable regression model was tested with patients nested within hospitals but found random effects at the hospital level did not contribute significantly to the fit of the model. Consequently, the final models adjusted only for withinparticipant correlation of the patients who had multiple encounters by using Huber-White sandwich estimators clustered at the patient level. ${ }^{19} 20$ The model's discrimination was assessed by the area under the receiveroperating curve (AUROC) and its calibration by the Hosmer-Lemeshow test. ${ }^{23}$

\section{RESULTS}

Among 4476 qualifying hypoglycemia study encounters, $1095(24.5 \%)$ had readmission to the ER/hospital within 30 days and 158 (14.4\%) of these encounters with readmission met the hypoglycemia-related criteria. All nine geographic divisions of the USA were represented among 116 contributing hospitals with the largest number from the Middle Atlantic (13\%) and smallest from the Pacific $(6 \%)$. Facilities contributing data to the analysis were mostly in an urban setting (88\%) and $45 \%$ were teaching hospitals.

The unadjusted, univariate results for the study encounters are listed in tables 1 and 2. Patients who had a readmission within 30 days were somewhat younger than those without readmission. African-American race and Medicare or Medicaid as payer status were more common among encounters with a 30-day readmission compared with those without readmission. Encounters among patients receiving care in an institutional setting (hospital, nursing home ( $\mathrm{NH})$, long-term care exposure (LTC), or transfer from hospice) within the preceding 90 days were almost twice as likely to demonstrate 30-day readmission. Study encounters with type 1 diabetes were more likely to be readmitted and have hypoglycemic readmissions compared with encounters with type 2 diabetes. Of the 1095 readmitted patients, $67.5 \%$ were classified as ER (with or without use of observational bed), and $74.1 \%$ of patients who were readmitted with hypoglycemia ( $\mathrm{n}=117$ out of 158) were also readmitted through the ER.

The chronic comorbidity burden was consistently higher for encounters with 30-day readmission as was the mean Charlson Comorbidity Index (CCI; table 2).

Intensive care unit exposure within the first $48 \mathrm{~h}$ was also higher in encounters with 30-day readmission. Mean baseline hemoglobin and estimated glomerular filtration rate were lower in encounters with readmission than in those not followed by a readmission.

In the regression analysis, one of the most strongly associated factors with all-cause 30-day readmission was 
Table 1 Demographic and encounter characteristics

\begin{tabular}{|c|c|c|c|c|c|c|c|c|c|}
\hline & \multicolumn{9}{|c|}{ Overall study cohort } \\
\hline & \multicolumn{6}{|c|}{ Readmitted } & \multirow{2}{*}{\multicolumn{2}{|c|}{$\begin{array}{l}\text { (B) Not } \\
\text { readmitted } \\
n=3381\end{array}$}} & \multirow{3}{*}{$\begin{array}{l}\text { p Value } \\
\text { (A) vs (B) } \\
\text { p Value }\end{array}$} \\
\hline & \multicolumn{2}{|c|}{$\begin{array}{l}(\mathrm{A}) \text { All } \\
\text { readmitted } \\
n=1095\end{array}$} & \multicolumn{2}{|c|}{$\begin{array}{l}\text { (A1) Нуро } \\
n=158\end{array}$} & \multicolumn{2}{|c|}{$\begin{array}{l}\text { (A2) } \\
\text { Non-hypo } \\
n=937\end{array}$} & & & \\
\hline & $\mathbf{n}$ & Per cent & $\mathbf{n}$ & Per cent & $\mathbf{n}$ & Per cent & $\mathbf{n}$ & Per cent & \\
\hline \multicolumn{10}{|l|}{ Age at admission, years } \\
\hline $6-17$ & 11 & 1.0 & 0 & 0.0 & 11 & 1.2 & 54 & 1.6 & $<0.001$ \\
\hline $18-24$ & 18 & 1.6 & 1 & 0.6 & 17 & 1.8 & 79 & 2.3 & \\
\hline $25-34$ & 77 & 7.0 & 11 & 7.0 & 66 & 7.0 & 151 & 4.5 & \\
\hline $35-44$ & 118 & 10.8 & 29 & 18.4 & 89 & 9.5 & 260 & 7.7 & \\
\hline $45-54$ & 190 & 17.4 & 28 & 17.7 & 162 & 17.3 & 503 & 14.9 & \\
\hline $55-64$ & 220 & 20.1 & 35 & 22.2 & 185 & 19.7 & 712 & 21.1 & \\
\hline $65-74$ & 194 & 17.7 & 24 & 15.2 & 170 & 18.1 & 724 & 21.4 & \\
\hline$\geq 75$ & 267 & 24.4 & 30 & 19.0 & 237 & 25.3 & 898 & 26.6 & \\
\hline \multicolumn{10}{|l|}{ Gender } \\
\hline Male & 547 & 50.0 & 89 & 56.3 & 458 & 48.9 & 1588 & 47.0 & 0.104 \\
\hline Female & 548 & 50.0 & 69 & 43.7 & 479 & 51.1 & 1793 & 53.0 & \\
\hline \multicolumn{10}{|l|}{ Race } \\
\hline Caucasian & 530 & 48.4 & 65 & 41.1 & 465 & 49.6 & 1783 & 52.7 & $<0.001$ \\
\hline African-American & 474 & 43.3 & 85 & 53.8 & 389 & 41.5 & 1251 & 37.0 & \\
\hline Asian & 2 & 0.2 & 0 & 0.0 & 2 & 0.2 & 42 & 1.2 & \\
\hline Other known & 78 & 7.1 & 7 & 4.4 & 71 & 7.6 & 251 & 7.4 & \\
\hline Unknown & 11 & 1.0 & 1 & 0.6 & 10 & 1.1 & 54 & 1.6 & \\
\hline \multicolumn{10}{|l|}{ Payer type } \\
\hline Commercial & 129 & 11.8 & 22 & 13.9 & 107 & 11.4 & 516 & 15.3 & $<0.001$ \\
\hline Medicare & 513 & 46.8 & 65 & 41.1 & 448 & 47.8 & 1531 & 45.3 & \\
\hline Medicaid & 180 & 16.4 & 32 & 20.3 & 148 & 15.8 & 388 & 11.5 & \\
\hline Self-paid & 37 & 3.4 & 3 & 1.9 & 34 & 3.6 & 176 & 5.2 & \\
\hline Other & 55 & 5.0 & 12 & 7.6 & 43 & 4.6 & 160 & 4.7 & \\
\hline Unknown & 181 & 16.5 & 24 & 15.2 & 157 & 16.8 & 610 & 18.0 & \\
\hline 90-day pre-exposure to healthcare facility* & 530 & 48.4 & 83 & 52.5 & 447 & 47.7 & 877 & 25.9 & $<0.001$ \\
\hline \multicolumn{10}{|c|}{ Discharge disposition } \\
\hline Acute care facility & 20 & 1.8 & 1 & 0.6 & 19 & 2.0 & 44 & 1.3 & $<0.001$ \\
\hline $\mathrm{SNF} / \mathrm{NH}$ & 107 & 9.8 & 10 & 6.3 & 97 & 10.4 & 190 & 5.6 & \\
\hline Home & 852 & 77.8 & 122 & 77.2 & 730 & 77.9 & 2755 & 81.5 & \\
\hline Other & 28 & 2.6 & 0 & 0.0 & 28 & 3.0 & 75 & 2.2 & \\
\hline Unknown & 88 & 8.0 & 25 & 15.8 & 63 & 6.7 & 317 & 9.4 & \\
\hline \multicolumn{10}{|l|}{ Diabetes type } \\
\hline Type 1 & 361 & 33.0 & 68 & 43.0 & 293 & 31.3 & 921 & 27.2 & 0.001 \\
\hline Type 2 & 734 & 67.0 & 90 & 57.0 & 644 & 68.7 & 2460 & 72.8 & \\
\hline \multicolumn{10}{|l|}{ Reference encounter type } \\
\hline ER (without in-pt) & 740 & 67.6 & 117 & 74.1 & 623 & 66.5 & 2498 & 73.9 & $<0.001$ \\
\hline In-pt (with/without ER) & 355 & 32.4 & 41 & 25.9 & 314 & 33.5 & 883 & 26.1 & \\
\hline ICU exposure $\leq 48 \mathrm{~h}$ after admission & 56 & 5.1 & 9 & 5.7 & 47 & 5.0 & 99 & 2.9 & 0.001 \\
\hline
\end{tabular}

*Signifies hospital, nursing home or long-term care exposure within 90 days, or transfer from hospice.

$\mathrm{ER}$, emergency room; ICU, intensive care unit; in-pt, inpatient; $\mathrm{NH}$, nursing home; SNF, skilled nursing facility.

in-pt hospital/NH/LTC/hospice exposure within 90 days (table 3 ). Age was a statistically significant predictor of readmission after multivariate adjustment. Young adults (25-44) had a higher likelihood of readmission compared with other age groups, including the elderly. African-American race was associated with 30-day readmission. Several cardiovascular comorbidities associated with complications of diabetes were predictive of all-cause 30-day readmission. These included hypertension, cerebrovascular disease, congestive heart failure $(\mathrm{CHF})$, and cardiac dysrhythmias with ORs generally between 1.2 and 1.3. Other potential complications of diabetes such as chronic renal failure $(\mathrm{OR}=1.194, \mathrm{p}=0.039)$ also had a significant association with readmission. Mood disorders were a significant predictor of all-cause 30-day readmission as well $(\mathrm{OR}=1.349, \mathrm{p}=0.002)$. Obesity and substance-related disorders were non-significant but had $\mathrm{p}$ values $<0.1$. A larger sample size might determine more definitively the association of these clinically important variables. 
Table 2 Select comorbid conditions of the study cohort

\begin{tabular}{|c|c|c|c|c|c|c|c|c|c|}
\hline \multirow{5}{*}{$\begin{array}{l}\text { CCI } \\
\text { Mean (SD) }\end{array}$} & \multicolumn{9}{|c|}{ Overall study cohort } \\
\hline & \multicolumn{6}{|c|}{ Readmitted } & \multirow{2}{*}{\multicolumn{2}{|c|}{$\begin{array}{l}\text { (B) Not } \\
\text { readmitted } \\
n=3381\end{array}$}} & \multirow{4}{*}{$\begin{array}{l}\text { p Value } \\
\text { (A) vs (B) } \\
<0.001 \\
\text { p Value }\end{array}$} \\
\hline & $\begin{array}{l}\overline{(A) A} \\
\text { read } \\
\mathrm{n}=10\end{array}$ & itted & $\begin{array}{l}\text { (A1) } \\
\mathrm{n}=15\end{array}$ & уро & $\begin{array}{l}\text { (A2) } \\
\mathrm{n}=93\end{array}$ & on-hypo & & & \\
\hline & \multicolumn{2}{|c|}{$4.2(2.4)$} & \multicolumn{2}{|c|}{$3.9(2.2)$} & \multicolumn{2}{|c|}{$4.9(2.5)$} & \multicolumn{2}{|c|}{$3.3(2.0)$} & \\
\hline & $\mathbf{n}$ & Per cent & $\mathbf{n}$ & Per cent & $\mathbf{n}$ & Per cent & $\mathbf{n}$ & Per cent & \\
\hline Secondary malignancies & 28 & 2.6 & 0 & 0.0 & 28 & 3.0 & 44 & 1.3 & 0.006 \\
\hline Obesity & 175 & 16.0 & 14 & 8.9 & 161 & 17.2 & 438 & 13.0 & 0.013 \\
\hline Hypertension & 868 & 79.3 & 132 & 83.5 & 736 & 78.5 & 2343 & 69.3 & $<0.001$ \\
\hline Cardiac dysrhythmias, any & 302 & 27.6 & 37 & 23.4 & 265 & 28.3 & 600 & 17.7 & $<0.001$ \\
\hline Congestive heart failure & 327 & 29.9 & 37 & 23.4 & 290 & 30.9 & 649 & 19.2 & $<0.001$ \\
\hline Cerebrovascular disease & 152 & 13.9 & 19 & 12.0 & 133 & 14.2 & 303 & 9.0 & $<0.001$ \\
\hline COPD and bronchiectasis & 252 & 23.0 & 33 & 20.9 & 219 & 23.4 & 453 & 13.4 & $<0.001$ \\
\hline Chronic renal failure & 461 & 42.1 & 62 & 39.2 & 399 & 42.6 & 999 & 29.5 & $<0.001$ \\
\hline Mood disorders & 273 & 24.9 & 39 & 24.7 & 234 & 25.0 & 513 & 15.2 & $<0.001$ \\
\hline Substance-related disorders & 119 & 10.9 & 13 & 8.2 & 106 & 11.3 & 175 & 5.2 & $<0.001$ \\
\hline
\end{tabular}

$\mathrm{CCl}$, Charlson Comorbidity Index; COPD, chronic obstructive pulmonary disease.

Online supplementary figure S1 demonstrates the adjusted marginal probabilities of readmission by age category.
Diabetes type had a significant interaction effect with cerebrovascular disease $(\mathrm{p}=0.027)$ in the assessment of risk factors associated with all-cause 30-day readmission

Table 3 Risk factors associated with all-cause 30-day ER/hospital readmissions

\begin{tabular}{|c|c|c|c|}
\hline Covariate & OR & $\begin{array}{l}95 \% \mathrm{Cl} \text { based } \\
\text { on robust SEs }\end{array}$ & $p>|z|$ \\
\hline \multicolumn{4}{|l|}{ Demographics } \\
\hline \multicolumn{4}{|l|}{ Age } \\
\hline $6-17$ & 1.416 & (0.690 to 2.908$)$ & 0.343 \\
\hline $18-24$ & 1.333 & (0.778 to 2.281$)$ & 0.295 \\
\hline 25-34 & 2.334 & (1.629 to 3.346$)$ & $<0.001$ \\
\hline $35-44$ & 1.966 & (1.459 to 2.650$)$ & $<0.001$ \\
\hline $45-54$ & 1.443 & (1.109 to 1.878$)$ & 0.006 \\
\hline $55-64$ & 1.171 & (0.926 to 1.482$)$ & 0.188 \\
\hline $65-74$ & 1 & - & - \\
\hline 75 or older & 1.103 & (0.884 to 1.377$)$ & 0.384 \\
\hline Male gender (vs female) & 1.138 & (0.979 to 1.324$)$ & 0.092 \\
\hline African-American (vs all other races) & 1.427 & (1.083 to 1.878$)$ & 0.011 \\
\hline Type 2 diabetes (vs type 1 diabetes) & 1.179 & (0.933 to 1.489$)$ & 0.168 \\
\hline African-American racextype 2 diabetes vs type 1 diabetes (interaction term) & 0.770 & (0.555 to 1.068$)$ & 0.117 \\
\hline Medicaid insurance status (vs else) & 1.266 & (1.018 to 1.574$)$ & 0.034 \\
\hline Hospital//NH/LTC/hospice exposure within 90 days & 1.984 & (1.678 to 2.345$)$ & $<0.001$ \\
\hline \multicolumn{4}{|l|}{ Comorbid conditions } \\
\hline Cerebrovascular disease & 2.004 & $(1.253$ to 3.206$)$ & 0.004 \\
\hline Cerebrovascular diseasextype 2 diabetes vs type 1 diabetes (interaction term) & 0.549 & (0.322 to 0.935$)$ & 0.027 \\
\hline Secondary malignancies & 1.684 & (0.999 to 2.839$)$ & 0.050 \\
\hline Chronic obstructive pulmonary disease and bronchiectasis & 1.482 & (1.218 to 1.803$)$ & $<0.001$ \\
\hline Mood disorders & 1.349 & (1.117 to 1.629$)$ & 0.002 \\
\hline Cardiac dysrhythmias, any & 1.286 & (1.068 to 1.550$)$ & 0.008 \\
\hline Substance-related disorders & 1.263 & (0.962 to 1.657$)$ & 0.092 \\
\hline Hypertension & 1.236 & (1.009 to 1.513$)$ & 0.040 \\
\hline Congestive heart failure & 1.231 & (1.018 to 1.488$)$ & 0.032 \\
\hline Chronic renal failure & 1.194 & (1.009 to 1.414$)$ & 0.039 \\
\hline Obesity & 0.822 & (0.663 to 1.020$)$ & 0.075 \\
\hline \multicolumn{4}{|l|}{ Acuity } \\
\hline ICU exposure within $48 \mathrm{~h}$ after admission & 1.399 & (0.976 to 2.007$)$ & 0.068 \\
\hline
\end{tabular}

ER, emergency room; ICU, intensive care unit; LTC, long-term care exposure; $\mathrm{NH}$, nursing home. 
(table 3). Patients with cerebrovascular disease and type 1 diabetes were more likely to be readmitted within 30 days than patients without cerebrovascular disease, though the risk of 30-day readmission was similar for patients with and without cerebrovascular disease in type 2 diabetes. A similar but less pronounced trend was observed with African-American race (vs all other race categories) and diabetes type. African-Americans with type 1 diabetes had a greater probability of readmission which was not evident in African-Americans with type 2 diabetes (see online supplementary figure S2).

Although the main goal of the regression analysis was to identify the factors most strongly associated with 30-day readmission, the model was well calibrated for prediction (the observed and predicted deciles of risk were statistically similar as evidenced by the nonsignificant Hosmer-Lemeshow statistic $=10.17, \quad \mathrm{p}=0.25)$ and had a reasonably high AUROC $=0.68 ; 95 \%$ CI $(0.66$ to 0.70$)$.

The second model assessed risk factors associated with 30-day ER/hospital readmissions attributable to hypoglycemia based on the study definition (table 4). As in the first model, the hypoglycemia-related readmission analysis had good discrimination and calibration with AUROC $=0.72 ; 95 \%$ CI $(0.67$ to 0.76$)$ and HosmerLemeshow statistic $=7.85, \mathrm{p}=0.45$. Recent exposure to hospital/SNF/NH/hospice was again a strong predictor of hypoglycemia-related readmission as was AfricanAmerican race. A similar age distribution was noted as in the first model, with the highest adjusted risk of 30-day ER/hospital readmissions attributable to hypoglycemia seen in ages 35-44. Men were somewhat more likely to have hypoglycemia-related readmissions compared with women. Hypertension was significantly associated with 30-day hypoglycemia-related readmissions as were delirium, dementia, amnestic, and other cognitive disorders, a comorbidity not seen in the primary model. As in the primary model, obesity had a protective effect against 30-day hypoglycemia-related readmission.

While no laboratory measure was predictive of outcome in our primary model, the last blood glucose value (closest to discharge) had a linear relationship with the risk of hypoglycemic readmission (see online supplementary figure S3).

\section{DISCUSSION}

Lowering hospital readmission rates has become a primary target for the Centers for Medicare \& Medicaid Services due to the prevalence and associated costs of these encounters. ${ }^{24}$ There is a lack of high-quality data characterizing hospital and ER visits for hypoglycemia across a broad age range in both type 1 and 2 diabetes. We believe this is the first study to evaluate the risk of readmission following hospital or ER visits for hypoglycemia in patients with diabetes. The strength of this study is the real-world nature of the data from a large number of hospitals across the USA and the richness of time-stamped data, including laboratory values. The inclusion of both ER/hospital readmissions in this study is different than most readmission measures, but both settings were deemed relevant when assessing emergency medical treatment for hypoglycemia.

This observational study provides new insight into hospital and ER admissions related to hypoglycemia in

Table 4 Risk factors associated with 30-day hypoglycemia-related ER/hospital readmission

\begin{tabular}{|c|c|c|c|}
\hline Covariate & OR & $\begin{array}{l}95 \% \mathrm{Cl} \text { based } \\
\text { on robust SEs }\end{array}$ & $p>|z|$ \\
\hline \multicolumn{4}{|l|}{ Demographics } \\
\hline \multicolumn{4}{|l|}{ Age } \\
\hline $6-34$ & 1.533 & (0.689 to 3.409$)$ & 0.295 \\
\hline $35-44$ & 3.484 & (1.935 to 6.271$)$ & $<0.001$ \\
\hline $45-54$ & 1.562 & (0.867 to 2.817$)$ & 0.138 \\
\hline $55-64$ & 1.476 & (0.834 to 2.613$)$ & 0.181 \\
\hline $65-74$ & 1 & & \\
\hline 75 or older & 0.960 & (0.513 to 1.798$)$ & 0.899 \\
\hline Male (vs female) & 1.405 & (0.999 to 1.977$)$ & 0.051 \\
\hline African-American (vs all other races) & 1.722 & (1.218 to 2.434$)$ & 0.002 \\
\hline In-pt (vs ER encounter) & 0.704 & (0.477 to 1.038$)$ & 0.077 \\
\hline $\begin{array}{l}\text { Hospital or } \mathrm{NH} / \mathrm{LTC} \text { exposure within } 90 \text { days, or transferred from hospice } \\
\text { Comorbid conditions }\end{array}$ & 2.299 & (1.608 to 3.286$)$ & $<0.001$ \\
\hline Hypertension & 1.891 & (1.108 to 3.225$)$ & 0.019 \\
\hline Delirium, dementia and amnestic and other cognitive disorders & 1.794 & (1.034 to 3.111$)$ & 0.038 \\
\hline Obesity & 0.505 & (0.288 to 0.884$)$ & 0.017 \\
\hline \multicolumn{4}{|l|}{ Acuity } \\
\hline Respiratory failure, insufficiency, arrest (adult) & 2.369 & $(0.971$ to 5.780$)$ & 0.058 \\
\hline \multicolumn{4}{|l|}{ Laboratory values } \\
\hline Last blood glucose value recorded during encounter per $10 \mathrm{mg} / \mathrm{dL}$ & 1.025 & (1.009 to 1.041$)$ & 0.002 \\
\hline
\end{tabular}

ER, emergency room; in-pt, inpatient; LTC, long-term care exposure; $\mathrm{NH}$, nursing home. 
patients with diabetes and the risk factors for 30-day allcause and hypoglycemia-related readmissions. Lipska et $a l^{25}$ reported 30-day readmission rates of $18.1 \%$ (95\% CI $17.6 \%$ to $18.5 \%$ ) in 2010 among fee-for-service Medicare beneficiaries hospitalized for hypoglycemia. The present study shows a higher all-cause 30-day ER or hospital readmission rate of $24.5 \%$ on a more comprehensive diabetes population.

Geller $e t a l^{12}$ reported that ER visits associated with insulin-related hypoglycemia and errors in the USA occurred at an annual rate of nearly 97000 between 2007 and 2011. Approximately one-third of these ER visits resulted in hospitalization, and more than half of these hospitalizations had documentation of severe neurological sequelae. Further, patients 80 years and older were more likely to visit the ER and were nearly five times more likely to be admitted to the hospital. Lipska et al reported that rates of hypoglycemia-related hospital admissions among Medicare beneficiaries were increased between 1999 and 2011, but there was no significant trend when adjusted for the increased prevalence of diabetes during that timeframe. The authors also described elevated admission rates for hypoglycemia among patients $\geq 75$ years. ${ }^{25}$ By virtue of the fact that Geller et al featured only insulin-treated patients and Lipska $e t$ al focused on fee-for-service Medicare hospitalizations, they are not strictly comparable to the current patient population.

Previous studies have shown that independent risk factors for severe hypoglycemia events in patients with type 2 diabetes include longer duration of diabetes, intensive glycemic control, history of hypoglycemia, impaired drug clearance (eg, renal insufficiency), history of microvascular complications, lower education level, African-American race, and history of dementia. $^{726}$

The regression results of this study will allow clinicians to more easily determine what risk factors place a patient with diabetes at increased risk for readmission. Subsequently, these patients can be targeted for greater inpatient education prior to discharge and more intensive initiatives focused on transitions of care outside the hospital setting. This study's models suggest several types of patients are more likely to have an all-cause or 30-day hypoglycemia-related readmission-namely those with complications related to diabetes, those with a high comorbidity burden and/or recent hospital exposure, and those who may not be following prescribed treatments to maintain appropriate glucose levels. It is well established that heart disease, cerebrovascular disease, hypertension, and renal disease are complications of diabetes. $^{27}$ We found patients with these factors are at increased risk for readmission.

Moreover, discharge to a SNF is known to be a risk factor for all-cause readmission. ${ }^{28}$ Our study demonstrates that nearly half of readmitted patients had recent hospitalization or confinement in a SNF/HF/hospice within the previous 90 days. This predictor was strongly associated with both all-cause readmission and hypoglycemia-related readmission. Another risk factor indicative of a high comorbidity burden but not a complication of diabetes was chronic obstructive pulmonary disease (COPD). Physicians should ensure patients with these easy to identify risk factors have appropriate support to treat their diabetes after discharge.

The third variety of patient we observed to be at increased risk for readmission was young adults and those with substance-related disorders, mood disorders, and delirium/dementia (who were often elderly). It is notable that young adults were at increased risk of readmission even after adjusting for other factors, including diabetes type and comorbid conditions. While it is speculative, we theorize that the young adults and patients with substance abuse or mood or cognitive disorders are less likely to adhere to their treatment regimen. Dietary compliance may also have been a contributing factor for readmission among young adults and patients with cognitive disorders With these patients, we encourage increased patient education prior to discharge that emphasizes the importance of maintaining normal glucose levels, proper diet, and how best to manage a hypoglycemic event. It also seems appropriate to determine how well patients with delirium/dementia are being cared for outside the hospital setting given our findings. While young adults were at increased risk for readmission, the analysis demonstrates that certain comorbidities associated with advanced age (eg, delirium/dementia, CHF, cerebrovascular disease) are also strong predictors for readmission. For example, $\mathrm{CHF}$ and cerebrovascular disease were predictors of allcause readmission and delirium/dementia a predictor for hypoglycemia-related readmission. This study also shows an apparent protective effect of obesity on hypoglycemia-related readmission. As the database did not include antidiabetic agents in the home setting at the time of admission, this result may have been an artifact related to different medication use in overweight patients; insulin resistance may also have been a factor.

The association of higher last recorded blood glucose with hypoglycemia-related readmissions could reflect transition of care issues, perhaps related to suboptimal glycemic control at the time of discharge. Autonomic dysfunction related to antecedent hypoglycemic episodes may also increase the risk of subsequent hypoglycemia by impairing glucose counter-regulation as well as affecting hypoglycemic awareness. ${ }^{29}$

As has been reported in other studies, racial disparity may contribute to the significant association of African-American race with both readmission types. Lipska et $a l^{25}$ reported that African-American patients with diabetes had hospital admission rates for hypoglycemia that were four times higher compared with Caucasian patients with diabetes, though as discussed, the previous study is not strictly analogous to the current study. Racial disparities for diabetes-related readmissions were reported by Jiang et $a l^{30}$ but these were in more 
evidence at 180 days following index admission rather than 30 days. In that study, African-Americans and Hispanics were more likely to be in the youngest age groups and African-Americans had the highest rates of acute complications. Racial disparity may have contributed to the interaction effect noted in this study's analysis, as African-Americans with type 1 diabetes were at increased risk of 30-day readmission.

Socioeconomic factors have been associated with risk of ER revisits more than in-pt readmissions. In an analysis of the HCUP data across all conditions, Steiner et $a l^{31}$ reported higher ER revisit rates among younger patients with Medicaid and community-level income had a significant impact on ER visits. The impact of payer status in our readmission analysis may reflect socioeconomic factors impacting access to care and care coordination, as Medicaid patients had a greater risk of readmission after adjusting for other factors. In our analysis, behavioral health factors impacted readmission risk differently in that mood disorders were associated with all-cause readmission, and cognitive impairment and dementia were associated with hypoglycemia-related readmission. Garrison $e t a l^{32}$ previously reported the impact of psychiatric comorbidities on hospital readmission among adolescents with diabetes.

As a retrospective cohort study, this analysis is prone to a number of biases, most prominently selection bias. To mitigate this, all consecutive encounters that met our a priori inclusion criteria were included. That said, the generalizability of the predictive variables of 30-day readmission on patients outside the Health Facts database is unknown. The readmission rate in this study was high despite the inability to document readmissions outside the system. Though this data set has undergone rigorous quality control checks, billing data are not designed specifically for research purposes and potentially create misclassification bias. To mitigate this, this study's definition of hypoglycemia-related encounters was designed to favor specificity over sensitivity (eg, using primary diagnosis of hypoglycemia). The database did not include nadir glucoses which may have been recorded in the home setting. Similarly, administered glucose or glucagon may have impacted baseline blood glucose values, distorting their effect on readmission.

\section{CONCLUSION}

We have identified multiple factors associated with 30-day readmission among patients with an ER/hospital encounter for diabetic hypoglycemia. Recent exposure to an in-pt setting, SNF, NH, or hospice was the strongest predictive factor for all-cause readmission and hypoglycemia-related readmission. Adults under the age of 45 admitted to the hospital or ER with hypoglycemia were at greater risk of 30-day readmission. Other chronic comorbidities associated with 30-day readmission include hypertension, cerebrovascular disease, COPD/ bronchiectasis, CHF, mood disorders, and delirium/ dementia. Increasing values of last blood glucose (closest to discharge) were associated with 30-day hypoglycemia-related readmission. Racial and socioeconomic disparities in effective care transitions may be reflected by the observed effects of African-American race and Medicaid payer status on readmission. These data confirm and extend observations from clinical trials of the need to personalize glycemic targets to reduce the risk of recurrent encounters. ${ }^{33}$

Acknowledgements The authors acknowledge the assistance of Hsing-Ting $\mathrm{Yu}$, formerly of Cerner Corporation, in designing this analysis.

Contributors MFE, JPB, and BJH designed the study. RJT built the analytic file and created the database. BHN performed the statistical analyses. MFE, JPB, and BJH provided direction and interpreted the study results. MFE, SLK, and BHN wrote the manuscript. All authors contributed to discussion and reviewed/edited the manuscript. MFE is the guarantor.

Funding Eli Lilly and Company provided funding for this project.

Competing interests SLK, RJT, and MFE are and were employed by Cerner Corporation, which was contracted by Eli Lilly and Company for this project. Cerner Corporation owns and maintains the Health Facts database used in this analysis. BHN's company, OptiStatim, LLC, was contracted by Cerner Corporation to conduct the statistical analyses. JPB and BJH are fulltime employees of Eli Lilly and minor stockholders in that company.

Provenance and peer review Not commissioned; externally peer reviewed.

Data sharing statement No additional data are available.

Open Access This is an Open Access article distributed in accordance with the Creative Commons Attribution Non Commercial (CC BY-NC 4.0) license, which permits others to distribute, remix, adapt, build upon this work noncommercially, and license their derivative works on different terms, provided the original work is properly cited and the use is non-commercial. See: http:// creativecommons.org/licenses/by-nc/4.0/

\section{REFERENCES}

1. Zoungas S, Patel A, Chalmers J, et al., Advance Collaborative Group. Severe hypoglycemia and risks of vascular events and death. N Engl J Med 2010;363:1410-18.

2. Johnston SS, Conner C, Aagren M, et al. Evidence linking hypoglycemic events to an increased risk of acute cardiovascular events in patients with type 2 diabetes. Diabetes Care 2011;34:1164-70.

3. Duckworth WC, Abraira C, Moritz TE, et al., Investigators of the VADT. The duration of diabetes affects the response to intensive glucose control in type 2 subjects: the VA Diabetes Trial. J Diabetes Complicat 2011;25:355-61.

4. Gerstein HC, Miller ME, Byington RP, et al., Action to Control Cardiovascular Risk in Diabetes Study, Group. Effects of intensive glucose lowering in type 2 diabetes. $N$ Engl $J$ Med 2008;358:2545-59.

5. Turchin A, Matheny ME, Shubina M, et al. Hypoglycemia and clinical outcomes in patients with diabetes hospitalized in the general ward. Diabetes Care 2009;32:1153-7.

6. Bonds DE, Miller ME, Bergenstal RM, et al. The association between symptomatic, severe hypoglycaemia and mortality in type 2 diabetes: retrospective epidemiological analysis of the ACCORD study. BMJ 2010;340:b4909.

7. Bloomfield HE, Greer N, Newman D, et al. Predictors and consequences of severe hypoglycemia in adults with diabetes-a systematic review of the evidence. VA-ESP Project \#09-009, 2012.

8. McCoy RG, Van Houten HK, Ziegenfuss JY, et al. Increased mortality of patients with diabetes reporting severe hypoglycemia. Diabetes Care 2012;35:1897-901.

9. Finfer S, Liu B, Chittock DR, et al., Nice-Sugar Study Investigators. Hypoglycemia and risk of death in critically ill patients. N Engl J Med 2012;367:1108-18.

10. Seaquist ER, Anderson J, Childs B, et al. Hypoglycemia and diabetes: a report of a workgroup of the American Diabetes Association and the Endocrine Society. Diabetes Care 2013;36:1384-95. 
11. Potter J, Clarke P, Gale EA, et al. Insulin-induced hypoglycaemia in an accident and emergency department: the tip of an iceberg? BMJ (Clin Res Ed) 1982;285:1180-2.

12. Geller Al, Shehab N, Lovegrove MC, et al. National estimates of insulin-related hypoglycemia and errors leading to emergency department visits and hospitalizations. JAMA Intern Med 2014;174:678-86.

13. Ward A, Alvarez P, Vo L, et al. Direct medical costs of complications of diabetes in the United States: estimates for event-year and annual state costs (USD 2012). J Med Econ 2014;17:176-83.

14. Lingvay I. Hypoglycemia in type 2 diabetes-consequences and risk assessment. US Endocrinol 2011;7:95-102.

15. Leese GP, Wang J, Broomhall J, et al., Darts Memo Collaboration. Frequency of severe hypoglycemia requiring emergency treatment in type 1 and type 2 diabetes: a population-based study of health service resource use. Diabetes Care 2003;26:1176-80.

16. Quilliam BJ, Simeone JC, Ozbay AB. Risk factors for hypoglycemiarelated hospitalization in patients with type 2 diabetes: a nested case-control study. Clin Ther 2011;33:1781-91.

17. Stefan MS, Pekow PS, Nsa W, et al. Hospital performance measures and 30-day readmission rates. J Gen Intern Med 2013;28:377-85.

18. Elixhauser A, Steiner C, Palmer L. Clinical Classifications Software (CCS). U.S. Agency for Healthcare Research and Quality, 2014. https://www.hcup-us.ahrq.gov/toolssoftware/ccs/ccs.jsp\#overview

19. Williams RL. A note on robust variance estimation for clustercorrelated data. Biometrics 2000;56:645-6.

20. Woolridge JM. Econometric analysis of cross section and panel data. Cambridge, MA: MIT Press, 2002.

21. Austin PC, Tu J. Bootstrap methods for developing predictive models. Am Stat 2004;58:131-7.

22. Raftery A. Bayesian model selection in social research. In: Marsden PV, ed. Sociological methodology. Vol 25. Oxford: Blackwell, 1995:111-63.

23. Hosmer DW, Lemeshow S. Applied logistic regression. New York: Wiley, 2000.
24. Jencks SF, Williams MV, Coleman EA. Rehospitalizations among patients in the Medicare fee-for-service program. N Engl J Med 2009;360:1418-28.

25. Lipska KJ, Ross JS, Wang Y, et al. National trends in US hospital admissions for hyperglycemia and hypoglycemia among Medicare beneficiaries, 1999 to 2011. JAMA Intern Med 2014;174:1116-24.

26. Miller ME, Bonds DE, Gerstein HC, et al., Accord Investigators. The effects of baseline characteristics, glycaemia treatment approach, and glycated haemoglobin concentration on the risk of severe hypoglycaemia: post hoc epidemiological analysis of the ACCORD study. BMJ 2010;340:b5444.

27. Centers for Disease Control and Prevention. National diabetes fact sheet: national estimates and general information on diabetes and prediabetes in the United States, 2011. Atlanta, GA: U.S. Department of Health and Human Services, Centers for Disease Control and Prevention, 2011.

28. Mor V, Intrator $\mathrm{O}$, Feng $\mathrm{Z}$, et al. The revolving door of rehospitalization from skilled nursing facilities. Health Aff (Millwood) 2010;29:57-64.

29. Cryer PE. Hypoglycemia-associated autonomic failure in diabetes. Handb Clin Neurol 2013;117;295-307.

30. Jiang $\mathrm{HJ}$, Andrews R, Stryer D, et al. Racial/ethnic disparities in potentially preventable readmissions: the case of diabetes. Am J Public Health 2005;95:1561-7.

31. Steiner C, Barrett M, Hunter K. Hospital readmissions and multiple emergency department visits, in selected states, 2006-2007. Statistical brief \#90 Healthcare Cost and Utilization Project (HCUP) statistical briefs. Rockville, MD: Agency for Healthcare Research and Quality, 2010.

32. Garrison MM, Katon WJ, Richardson LP. The impact of psychiatric comorbidities on readmissions for diabetes in youth. Diabetes Care 2005;28:2150-4.

33. Ismail-Beigi F, Moghissi E, Tiktin M, et al. Individualizing glycemic targets in type 2 diabetes mellitus: implications of recent clinical trials. Ann Intern Med 2011;154:554-9. 